\title{
BMJ Open Time to market for drugs approved in Canada between 2014 and 2018: an observational study
}

\author{
Joel Lexchin (1)
}

To cite: Lexchin J. Time to market for drugs approved in Canada between 2014 and 2018: an observational study. BMJ Open

2021;11:e047557. doi:10.1136/ bmjopen-2020-047557

- Prepublication history and additional supplemental material for this paper are available online. To view these files, please visit the journal online (http://dx.doi.org/10.1136/ bmjopen-2020-047557)

Received 03 December 2020 Accepted 22 June 2021
Check for updates

(C) Author(s) (or their employer(s)) 2021. Re-use permitted under CC BY-NC. No commercial re-use. See rights and permissions. Published by BMJ.

School of Health Policy \& Management, York University Faculty of Health, Toronto, Ontario, Canada

Correspondence to

Dr Joel Lexchin;

jlexchin@yorku.ca

\section{ABSTRACT}

Objectives This study examines the length of time between when a patent application is filed in Canada for a new drug and when it is available for patients (time to market) and various components of that time. It also looks at whether various factors explain the time between patent application to New Drug Submission (NDS) and compares Canadian and American times. Drugs approved between 1 January 2014 and 31 December 2018 are examined. Design Descriptive study.

Data sources Websites from Health Canada, Food and Drug Administration, Merck Index, United States Patent and Trademark Office, WHO and previously published articles. Interventions None.

Primary and secondary outcomes The primary outcomes are time to market, time from patent application to NDS (pre-NDS time), review time, time from approval to availability (postapproval time) and factors that may influence the pre-NDS time. The secondary outcome is a comparison of Canadian and American review times and times between patent application and approval.

Results There were 113 drugs available for analysis. The median time to market was 11.80 years (IQR 9.40-14.05). The component median times were pre-NDS 10 years (IQR 8.05-12.80), review time 0.96 years (IQR $0.75-1.15$ ) and postapproval time 0.15 years (IQR $0.08-0.28$ ). Less than $8 \%$ of the pre-NDS time was explained by the factors that were analysed in a multiple linear regression equation. There was no statistically significant difference between Canadian and American pre-NDS times.

Conclusion Once a drug reaches the market, companies have a median of 8.2 years before the patent expires and generics can reach the market. Most of the time between the filing of a patent application and when a drug is marketed is determined by decisions that are largely under the control of the company.

\section{INTRODUCTION}

Since 1989, prescription drugs in Canada have been protected by patents for a 20 -year period from the date when the patent application is filed. ${ }^{1}$ Patents for medicines are typically filed early in the process of developing a new drug and a substantial portion of the 20 years can be consumed by a combination of preclinical and clinical testing and the regulatory review process.

\section{Strengths and limitations of this study}

This is the first Canadian study to examine the time between when a patent application is filed and when a drug is available to patients.

- Factors possibly affecting the time between when a patent application is filed and a New Drug Submission is filed were investigated.

- Canadian and American times were compared for regulatory reviews and time between when a patent application is filed and when a drug is approved.

- Data was not available for 61 out of 174 drugs that were approved.

- Much of the data came from Canadian government databases that have not been formally evaluated.

Innovative Medicines Canada (IMC), and its predecessors, the lobby group representing the research-based pharmaceutical companies has been advocating for at least two decades for an increase in patent life to compensate for the time that drugs spend from the date of filing of the patent application until when the drug is approved. ${ }^{2-7}$

The patent application to marketing time (time to market) can be divided into three relatively distinct time periods: patent application to the end of clinical trials/filing of a New Drug Submission (pre-NDS time); NDS to Notice of Compliance (NOC, authorisation to market) (review time); NOC to actual availability to patients (postapproval time). Pre-NDS and postapproval times are largely determined by the actions of companies (company time), whereas review time is mostly under the control of regulators. Lexchin examined new active substances (NAS, molecules never marketed before in Canada) approved from 1 January 2014 to 31 December 2018 and found that the mean review time was 403 days (95\% CI 374 to 433 ) and the mean postapproval time was 133 days (95\% CI 101 to 165$){ }^{8}$ In other research, he showed that the time from patent application to NOC went from 6.14 years in 2009 to 11.5 
years in 2018. ${ }^{9}$ However, there has not been any literature looking specifically at the pre-NDS time for drugs approved in Canada nor the various factors that might influence this time period. There is also no current research into the overall time to market.

This study has primary three goals: first, to determine the length, in years, of the time to market and its components-pre-NDS time, review time and postapproval time; second, to examine the factors that might influence the pre-NDS time; and finally, to determine the relative contributions of company time and regulatory time to the time to market. Finally, although the Comprehensive Economic Trade Agreement between Canada and the European Union provides for up to 2 years additional patent protection time, ${ }^{10}$ it seems likely that IMC would like to see even longer periods. ${ }^{71}$ One argument advanced by industry is that longer patent protection is needed to compensate for pre-NDS time. The USA already offers a 5-year extension in additional patent protection, up to a maximum of 14 years, and therefore, a final goal is to compare Canadian and American review times and times between the time when a patent application is filed in each country and regulatory approval in each country (pre-NDS+review times). Comparing the times in the two countries can help determine the validity of the position advanced by the industry.

\section{METHODS}

\section{Data sources}

A previous paper by Lexchin ${ }^{9}$ provided a list of all NAS approved in Canada between 1 January 2014 and 31 December 2018 along with their brand and generic names, dates when the companies applied for a NDS, dates when the drugs received a NOC, whether the drugs received a standard review (300 days) or an expedited review (priority review-180 days, NOC with conditions review-200 days), whether they were small molecule drugs or biologics and the date when a patent application was filed. Marketing dates came from a second study by Lexchin. ${ }^{8}$

The number of patients in the pivotal trials and whether the trials used a clinical or surrogate outcome was determined from the Summary Basis of Decision ${ }^{12}$ a document which, among other information, explains the clinical basis for the approval decision. The WHO Anatomical Therapeutic Chemical (ATC) database ${ }^{13}$ was used to classify products into the second level (pharmacologic or therapeutic subgroup). Searches of both the Summary Basis of Decision website and the WHO ATC database were performed on 5 November 2020.

A list of drugs approved by Health Canada that received orphan drug status from the US Food and Drug Administration (FDA) was generated from two web sites: https:/ / wayback.archive-it.org/7993/20170404174205/https:/ / www.fda.gov/Drugs/DevelopmentApprovalProcess/ HowDrugsareDevelopedandApproved/DrugandBiolo gicApprovalReports/NDAandBLAApprovalReports/ ucm373420.htm (drugs approved from 2014 to 2016) and https://www.fda.gov/drugs/nda-and-bla-approvals/newmolecular-entity-nme-drug-and-new-biologic-approvals (drugs approved in 2017 and 2018). First in class status, as rated by the FDA, came from annual reports found at https://www.fda.gov/drugs/development-approvalprocess-drugs / new-drugs-fda-cders-new-molecular-entities-and-new-therapeutic-biological-products (drugs approved from 2015 to 2018) and http://wayback. archive-it.org/7993/20170111075020/http://www.fda. gov/Drugs/DevelopmentApprovalProcess/DrugInnovation/ucm429247.htm (drugs approved in 2014).

The US review time and time between patent application filing and FDA approval came from a supplementary file from the article by Beall and colleagues. ${ }^{14}$ The data in the article of Beall et al was supplemented by searching Drugs@FDA (https://www.accessdata.fda.gov/scripts/ cder/daf/index.cfm) and Licensed Biological Products with Supporting Documents (https://www.fda.gov/ vaccines-blood-biologics/licensed-biological-productssupporting-documents) for information about the date when an Investigation New Drug application was filed and when FDA approval was granted. Additional information about patent application filing dates was gathered by searching either the Approved Drug Products with Therapeutic Equivalence Evaluations

('Orange Book') (https://www.accessdata.fda.gov/ scripts/cder/ob/index.cfm) or the Merck Index ${ }^{15}$ for the patent number of the first expiring patent. This number was then entered into the online United States Patent and Trademark database ${ }^{16}$ to determine the date when the patent application was filed.

All data was entered into an Excel file.

\section{Data analysis}

The various time periods were defined and calculated as follows and expressed in years:

Pre-NDS time: patent application filing date subtracted from NDS date.

Review time: NDS date subtracted from NOC date.

Postapproval time: NOC date subtracted from marketing date.

Time to market: patent application filing date subtracted from marketing date.

Company time: pre-NDS time+postapproval time.

A multiple linear regression model was estimated to assess the association of various factors with the outcome variable, PN years, defined as the number of years between patent application filing and NDS:

PN years ${ }_{i=} \beta_{0}+\beta_{1} \log \left(P T\right.$ trial $\left._{i}\right)+\beta_{2}$ Biologic $_{i}+\beta_{3}$ ATC type

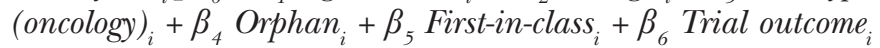
$+\varepsilon_{i}$

The number of patients enrolled in pivotal clinical trials, PTs trial, was log transformed and was included to test whether recruitment of patients may be more difficult for trials requiring large numbers of patients. Biologics were included on the basis that they are more difficult to synthesise than small molecules and therefore, would 
have longer laboratory time. ATC type was dichotomised to oncology versus all others, because aside from antineoplastics (30 drugs), there were small numbers in all other categories. Orphan drug status was included because recruitment of patients may be difficult for drugs for orphan diseases because of the low number of patients. First-in-class drugs were included because they are more likely to offer significant therapeutic advantages over existing drugs, ${ }^{917}$ and therefore, companies would prioritise the development of these drugs. Finally, trials using a surrogate outcome were presumed to be completed more rapidly than trials with a clinical outcome.

Canadian and American times were not normally distributed and descriptive data were presented as medians and times were compared using the Mann-Whitney nonparametric test with $\mathrm{p}<0.05$.

The distribution of drugs with and without data availability was compared using the Kolmogorov-Smirnov test with $\mathrm{p}<0.05$ on the basis of their ATC classification to determine if the drugs that were included were different than those that were excluded.

Calculations were performed using Prism V.9.0 (GraphPad Software LLC).

\section{Patients and public involvement}

No patients were involved in this study. There was no public involvement in this study.

\section{RESULTS}

There were 174 NAS approved over the 5-year time period. Twenty-nine did not have a marketing date and 32 did not have a date when the patent application was filed, leaving 113 drugs for analysis (figure 1). The characteristics of the drugs are presented in table 1 . One product did not have an ATC classification. Trial size was not available for two drugs.

The median time to market was 11.80 years (IQR 9.40-14.05). The component median times were: preNDS 10.00 years (IQR 8.05-12.80), review time 0.96 years

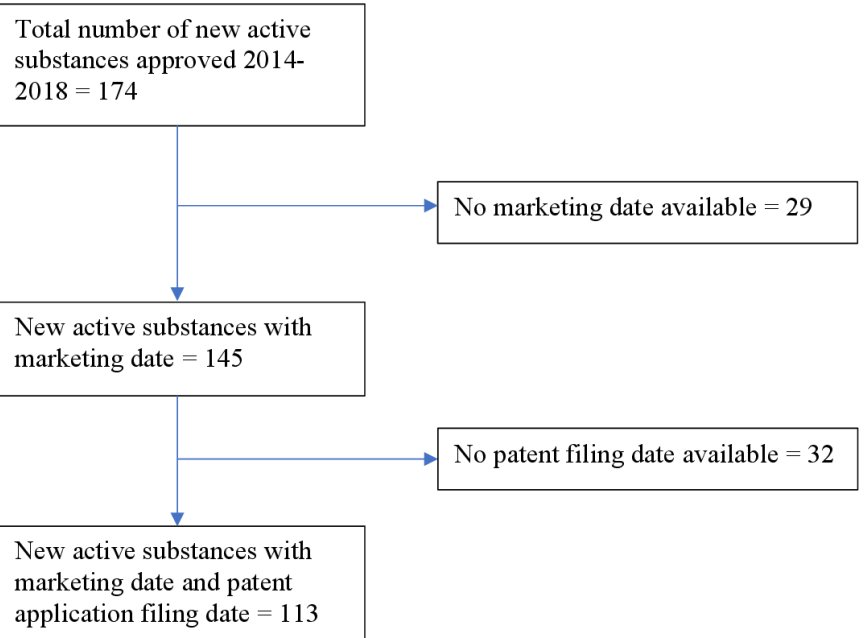

Figure 1 Selection of drugs. 
Table 2 Comparison of Canadian and USA times

\section{Median review time in years}

(IQR)

Median patent application to approval time in years (IQR)

\begin{tabular}{llll}
\hline Canada & USA & Canada & USA \\
\hline $0.96(0.75-1.15)$ & 0.85 (0.61-1.00) & $11.40(9.20-13.85)$ & 11.50 (9.45 to 14.85) \\
$\mathrm{P}=0.0033$ (Mann-Whitney test) & $\mathrm{P}=0.2324$ (Mann-Whitney test) & \\
\hline
\end{tabular}

(IQR 0.75-1.15) and postapproval time 0.15 years (IQR $0.08-0.28)$. The pre-NDS time was $84.7 \%$ of the total time to market and the complete company time (pre-NDS time+postapproval time) was 10.15 years or $86.0 \%$ of the time to market. Regulatory time (review time) was 0.96 years or $8.1 \%$ of the time to market.

The multiple linear regression analysis only explained $7.8 \%$ of the pre-NDS time. None of the individual factors was statistically significant. The variance inflation factors for the individual factors ranged from 1.094 to 1.759, indicating that multicollinearity among the predictor variables was not a concern. (Online supplemental file 1 presents the results of the regression analysis.)

There were 113 drugs approved by Health Canada and 111 approved by the FDA available for a comparison of review times and 113 Canadian drugs and 101 American drugs for a comparison of the time between filing the patent application and approval. Time in Canada between patent application filing and approval was a median of 11.40 years (IQR 9.20-13.85) and in the USA was 11.50 (IQR 9.45-14.85) ( $\mathrm{p}=0.2324$, Mann-Whitney test). Review time in Canada was a median of 0.96 years (IQR 0.75-1.15) and in the USA was 0.85 years (IQR 0.61-1.00) ( $\mathrm{p}=0.0033$, Mann-Whitney test) (table 2).

The Anatomical Therapeutic Chemical distribution of drugs with and without data availability was not statistically significantly different $(p=0.8186$, KolmogorovSmirnov test).

\section{DISCUSSION}

Based on the sample of new drug approvals analysed, it takes a median of 11.80 years from when a patent application is filed until the drug is available to be prescribed in Canada, leaving a median of 8.2 years of patent time remaining. The pre-NDS time accounts for $84.7 \%$ of the time to market. However, the factors that were examined explained less than $8 \%$ of the pre-NDS time. Other factors that could be investigated in future research require access to additional data and could include time taken to do the animal trials, whether the animal trials run consecutively or concurrently with the human trials, whether the three phases of human trials run consecutively or concurrently, the geographic location of the human trials, which might impact recruitment, whether the trials are single or multisite and time taken for ethical approval of human trials.
Most of the time to market is predominantly under the control of the company ( $86.0 \%$ of the time). Of course, the activities of the companies in the pre-NDS time are partly governed by the requirements imposed directly by Health Canada and indirectly by the agency's adoption of guidelines developed by the International Council for Harmonisation of Technical Requirements for Pharmaceuticals for Human $\mathrm{Use}^{18}$ on laboratory, animal and human testing. But companies are still primarily responsible for the design of the clinical trials, such as whether to use an inferiority or superiority design, the population and indication tested and the number of patients recruited. Similarly, not all of the time in the review process is due to Health Canada as it may be waiting for companies to respond to questions or to provide additional data.

Monopoly selling time can extend beyond the point when the patent expires. Out of 121 drugs with the highest sales in Canada between 2009 and 2015 inclusive, the 63 with a generic competitor had a mean market exclusivity time of 12.3 years and the 58 drugs without a competitor had been available for a median of 14.7 years. ${ }^{19}$ Provisions in the Comprehensive Economic and Trade Agreement (CETA) between Canada and the European Union provided for an extension of Canadian patents for prescription drugs by up to 2 years after the agreement came into force in September 2017. ${ }^{10}$ The Parliamentary Budget Office (PBO) estimated that, had the CETA provisions been in place in 2015 , the amount spent on drugs in that year would have increased by $\$ 392$ million (in 2015 dollars ${ }^{20}$ in addition to the existing $\$ 30.1$ billion already spent. ${ }^{21}$ The $\mathrm{PBO}$ also believed that given the rapid evolution of the Canadian drug market, its estimate was likely to understate future expenditures. Additional patent protection would serve to increase overall annual expenditures.

The times reported in this study differ somewhat from those previously reported by Lexchin ${ }^{89}$ because of differences in the sample of drugs that were analysed. The shorter review time in the USA compared with Canada is not surprising for a couple of reasons: first, a higher percentage of drugs go through one of the shorter review pathways in the USA $(48 \%)^{22}$ versus in Canada $(29.7 \%) .{ }^{23}$ Second, average drug review times for the FDA are about 100 days shorter than those for Health Canada. ${ }^{24}$ The 11.50 years median time in the USA from filing a patent 
application until approval is somewhat shorter than the $12.1-12.4$ years as reported by Beall and colleagues ${ }^{14}$ possibly due to the difference in the sample of drugs in the two studies.

\section{Limitations}

Thirty-five per cent (61 out of 174) of the drugs approved between 2014 and 2018 could not be analysed because data was missing for either the date of patent application or the date of marketing. The drugs included and excluded did not differ in the distribution of their ATC level 2 categories and therefore, on this measure, were similar indicating that if the data were available for the missing drugs that the results would not have changed. Much of the data used came from a secondary analysis of a number of Canadian government databases. Those databases have been assembled and published based on information either provided to or generated by the federal government and have been extensively used by researchers and are regarded as authoritative, but no formal evaluation of their quality/validity has been conducted. Information about the total time needed for clinical trials could not be collected since Health Canada does not publish the date when companies submit a Clinical Trial Application. A Clinical Trial Application is necessary before clinical trials can begin. In some cases, the total number of patients enrolled in clinical trials was an approximation as, at times, the Summary Basis of Decision did not make it clear whether patients taking placebo were included in the totals and sometimes vague terminology was used, such as 'approximately x patients were enrolled'. It was also not always clear which studies were considered pivotal and a decision about that point had to be inferred from other information in the Summary Basis of Decision.

\section{CONCLUSION}

Once a drug reaches the market, companies have a median of 8.2 years before the patent expires and generics can reach the market, without accounting for the extra patent time allowed under the free trade agreement between Canada and the European Union. Most of the time between the filing of a patent application and when a drug is marketed is determined by decisions that are largely under the control of the company. In addition, the argument for additional patent protection time in order to compensate for the time between filing for a patent and filing for approval does not appear to be valid since pre-NDS times in the USA and Canada are almost identical despite the extra patent time afforded by the USA. Therefore, if companies feel more monopoly marketing time is needed, they should explore ways to reduce preNDS time and postapproval time, in addition to calling for changes to the regulatory system.

Acknowledgements Oliver Spicer provided valuable statistical advice.

Contributors $\mathrm{JL}$ came up with the idea for this study, gathered and analysed the data and wrote the manuscript.
Funding The authors have not declared a specific grant for this research from any funding agency in the public, commercial or not-for-profit sectors.

Competing interests From 2017 to 2020, JL received payments for being on a panel at the American Diabetes Association, for talks at the Toronto Reference Library, for writing a brief in an action for side effects of a drug for Michael F Smith Lawyer, and a second brief on the role of promotion in generating prescriptions for Goodmans LLP and from the Canadian Institutes of Health Research for presenting at a workshop on conflict of interest in clinical practice guidelines. He is currently a member of research groups that are receiving money from the Canadian Institutes of Health Research and the Australian National Health and Medical Research Council. He is a member of the Foundation Board of Health Action International and the Board of Canadian Doctors for Medicare. He receives royalties from University of Toronto Press and James Lorimer \& Co Ltd for books he has written.

Patient consent for publication Not required.

Ethics approval All data was publicly available and therefore ethics consent was not required.

Provenance and peer review Not commissioned; externally peer-reviewed.

Data availability statement Data are available in a public, open access repository. Extra data can be accessed via the Dryad data repository at http://datadryad.org/ with the doi: 10.5061/dryad.c2fqz616t.

Supplemental material This content has been supplied by the author(s). It has not been vetted by BMJ Publishing Group Limited (BMJ) and may not have been peer-reviewed. Any opinions or recommendations discussed are solely those of the author(s) and are not endorsed by BMJ. BMJ disclaims all liability and responsibility arising from any reliance placed on the content. Where the content includes any translated material, BMJ does not warrant the accuracy and reliability of the translations (including but not limited to local regulations, clinical guidelines, terminology, drug names and drug dosages), and is not responsible for any error and/or omissions arising from translation and adaptation or otherwise.

Open access This is an open access article distributed in accordance with the Creative Commons Attribution Non Commercial (CC BY-NC 4.0) license, which permits others to distribute, remix, adapt, build upon this work non-commercially, and license their derivative works on different terms, provided the original work is properly cited, appropriate credit is given, any changes made indicated, and the use is non-commercial. See: http://creativecommons.org/licenses/by-nc/4.0/.

ORCID iD

Joel Lexchin http://orcid.org/0000-0001-5120-8029

\section{REFERENCES}

1 Smith M. Patent protection for pharmaceutical products in Canada - chronology of significant events. Ottawa: Parliament of Canada, 2000. Available: http://publications.gc.ca/collections/Collection-R/ LoPBdP/PRB-e/PRB9946-e.pdf

2 Rx\&D. Information guide, second edition. Ottawa: Rx\&D, 2003.

3 Rx\&D. Improving health through innovation: a new deal for Canadians. Ottawa: Rx\&D, 2003.

4 Rx\&D. Towards increasing research and development in Canada: a new innovative pharmaceutical strategy. Ottawa: Rx\&D, 2004.

$5 \mathrm{Rx} \& \mathrm{D}$. Rx\&D response to sharpening Canada's competitive edge. Ottawa: Rx\&D, 2008.

6 Rx\&D. Review of federal support to research \& development expert panel submission. Ottawa: Rx\&D, 2010.

7 Innovative Medicines Canada. Intellectual property. Ottawa:, 2019. Available: http://innovativemedicines.ca/innovation/intellectualproperty/

8 Lexchin J. How long do new medicines take to reach Canadian patients after companies file a submission: a cohort study. PLoS One 2020;15:e0240966.

9 Lexchin J. Development time and patent extension for prescription drugs in Canada: a cohort study. Int J Health Policy Manag 2020. doi:10.34172/ijhpm.2020.100. [Epub ahead of print: 23 Jun 2020].

10 Health Canada. Guidance document: certificates of supplementary protection. Ottawa;, 2019. Available: https://www.canada.ca/en/ health-canada/services/drugs-health-products/drug-products/ applications-submissions/guidance-documents/register-certificates/ certificate-supplementary-protection-regulations.html

11 Innovative Medicines Canada. Comparison of Canadian and nonCanadian pharmaceutical intellectual property (IP) regimes; $\mathrm{Nd}$. Available: http://innovativemedicines.ca/wp-content/uploads/2016/ 06/CETA-International-Comparison-EN.jpg 
12 Government of Canada. The drug and health products register, 2020. Available: https://hpr-rps.hres.ca/reg-content/summary-basisdecision-result.php?lang=en\&term=

13 WHO Collaborating Centre ffor Drug Statistics Methodology. ATC/ DDD index 2020: Norwegian Institute of public health, 2019. Available: https://www.whocc.no/atc_ddd_index/

14 Beall RF, Hwang TJ, Kesselheim AS. Pre-market development times for biologic versus small-molecule drugs. Nat Biotechnol 2019;37:708-11.

15 Royal Society of Chemistry. The Merck index online 2021, 2021. Available: https://www.rsc.org/merck-index

16 United States Patent and Trademark Office. USPTO patent and full-text and image database; nd. Available: http://patft.uspto.gov/ netahtml/PTO/search-bool.html

17 Lexchin J. How safe and innovative are first-in-class drugs Approved by Health Canada: a cohort study. Healthc Policy 2016;12:65-75.

18 International Council for Harmonisation of Technical Requirements for Pharmaceuticals for Human Use. ICH guidelines 2020, 2020. Available: https://www.ich.org/page/ich-guidelines
19 Lexchin J. Market exclusivity time for top selling originator drugs in Canada: a cohort study. Value Health 2017;20:1139-42.

20 Office of the Parliamentary Budget Officer. Patent restoration and the cost of pharmaceuticals. Ottawa: Office of the Parliamentary Budget Officer, 2018.

21 Canadian Institute for Health Information. National health expenditure trends 2021, 2021. Available: https://www.cihi.ca/en/national-healthexpenditure-trends

22 Downing NS, Krumholz HM, Ross JS, et al. Regulatory Watch: characterizing the US FDA's approach to promoting transformative innovation. Nat Rev Drug Discov 2015;14:740-1.

23 Lexchin J. Health Canada's use of its priority review process for new drugs: a cohort study. BMJ Open 2015;5:e006816.

24 Centre for Innovation in Regulatory Science. New drug approvals in six major authorities 2010-2019: focus on the availability of medicines and company size. London: Centre for Innovation in Regulatory Science, 2020. 